\title{
Map Application Using Augmented Reality Technology for Smart Phones
}

\author{
J.D.Jadhav \\ Department of Computer \\ Engineering. \\ Bharti Vidyapeeth \\ college of engineering \\ for women \\ Pune, Maharshtra \\ India.
}

\author{
Salve Pratiksha, \\ Sonawane Ashwini \\ Department of Computer \\ Engineering. \\ Bharti Vidyapeeth \\ college of engineering \\ for women \\ Pune, Maharshtra \\ India.
}

\author{
Gaikwad Sunita, \\ Deepika Kumari \\ Department of Computer \\ Engineering. \\ Bharti Vidyapeeth \\ college of engineering \\ for women \\ Pune, Maharshtra \\ India.
}

\begin{abstract}
Global positioning system (GPS) finds nearby doctors like ATM, Bank, Cafe, Bus Stop, Restaurant, Hotel, Movie Theatre, etc. using Location and compass Sensors. The Location Sensor hardware can determine the phone's latitude and longitude as well as place name. This application can use in emergency case; we are able to find location of nearby place and place details. The application allows you to set radius and it also supports Augmented Reality (AR). It automatically finds your current location and plots it on a map.
\end{abstract}

Keywords: Mobile augmented reality; Location based services; Compass sensor; Global positioning system;

Street

data.

discover the augmented reality experience in

\section{INTRODUCTION}

Augmented reality (AR) is a live direct or indirect view of a physical, real-world environment whose elements are augmented (or supplemented) by computer-generated sensory input such as sound, video, graphics or GPS data.

The AR technology blurs the line between what's real and what's not by simply enhancing the reality around you. It provides a different perspective of the physical world around you with the help of visual media. The term augmented reality simply means enhanced reality. The smart phones help to form of visual data imagery, which was normally not visible to you.

With mobile Augmented Reality the computer, or rather, the smart phone is used to extend or improve the quality and quantity of relevant contextual information available at a certain time and place. Most common so far, is a combination of information coming from the smart phones camera.

This paper provides a starting point for anyone interested in using Augmented Reality in Smart devices for location based services. 


\section{RELATED WORKS}

There are various applications that uses augmented Reality. Some of them are:

\subsection{A Mobile Augmented} Reality Service Model based on Street Data, its and Implementation.[1]

In this the popularity of smart devices and location services is increases day by day and this services are provided by the augmented reality technique. This technology utilizes the embedded Sensors in the mobile device. It helps to user to get more information about a particular location. The app uses the compass and camera view finder sensors to locate places and give the right information on right place.

\subsection{Geo-location based} Augmented Reality.[2]

The augmented reality is the latest technology which blends and build the computer generated animation and graphics over the physical world. The geo-based augmented reality is the combination of the augmented reality, GPS and location based system these three of technologies build the innovative technology.

\subsection{Implementation of} Augmented Reality System for Smart Phones Advertisement.[3] Here this used the marker less augmented reality system on smart phones to design and implement the Smartphone application service. It has an efficiently conveying information on advertisements to users. Here researchers implanted the two-way communication in between the augmented reality and the users through the mark less augmented reality application.

\subsection{Mobile Augmented Reality.[4]}

It is the branched from the virtual reality in its earlier days the augmented reality used the hardware devices containing a lot of sensors but now a day it can be built in mobile device and because of this the user can access it comfortably and very easily.

\subsection{AR Tracking.[5]}

This approach of AR tracking can be data based which is the combination of both sensors as well as visions. It pays the attention to the position, movement, speed and the direction of the object. Now-a-days most of the AR implementations in the mobile device use the sensor-based tracking.

\section{PROPOSED SYSTEM ARCHITECTURE IN AUGMENTED REALITY USING ANDROID}

The proposed system is a location based system and its architecture as shown in figure 1 containing various module

1) UI-user interface

2) Google Map Module

3) Find Place Module

4) Augmented Reality Module 


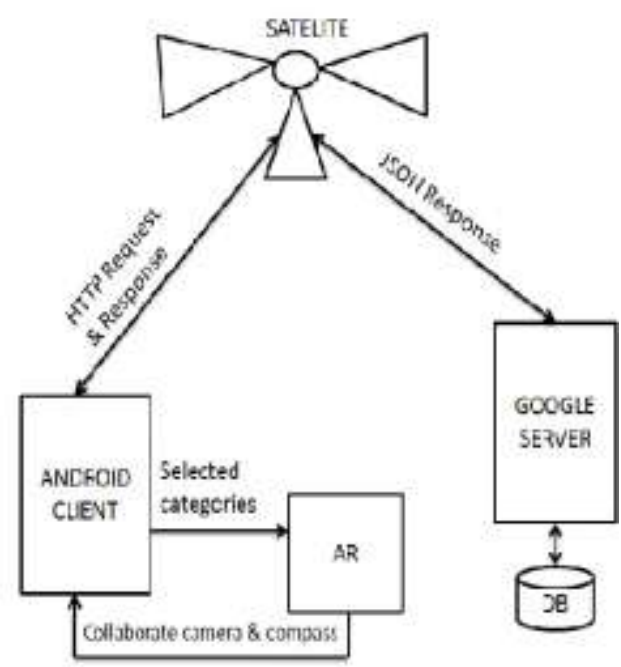

Fig 1. Block Diagram

In this system the client i.e. Android use will select the categories and location and give it to the AR will collaborate with the camera and compass sensor of Android.

For the location finding client will send HTTP request to satellite through GPS system. satellite will then collect the latitude and longitude position of the user then it will send that to the position to the Google server will search near by with radius. it will then fetch the information in the form of name ,id and address of particular latitude and longitude position from the database.

As soon as the result are found the Google server will send JSON response to the satellite then satellite will response to the HTTP request and will give location to the client.

\section{Advantages of Augmented Reality}

1) $\mathrm{AR}$ increase information and knowledge. People can share experiences with each other in real world over long distances.

2) Games that provides an even more "real" experience.

3) Things come to life on people's mobile Form of Escapism.

\section{Disadvantage of Augmented Reality}

1) Spam and security.

2) UX(User Experience): Using AR can be inappropriate in social situation.

3) Openness : Another people can develop there own layers of content to display.

\section{EXAMPLES OF AUGMENTED REALITY}

\subsection{Tourism}

Augmented reality can be used in the field of tourism to enhance user experience during visits. In Bordeaux, for example, it is possible to view the current monuments in the context of the eighteenth century by simply downloading an application on a tablets.

\subsection{Business}

There are Multiple uses of augmented reality in a business content .In some physical stores, augmented reality allows users to try on clothes without going to the fitting room.

\subsection{Automobiles}

In some automobile models, augmented reality technology is used to display information on the windshield. The display 
mode provides information regarding speed ,obstacles, the width of the roads and traffics.

\subsection{E-Commerce}

On a commercial site, augmented reality applies to many areas . some opticians offer consumers the opportunity to try on glasses before deciding on a pair and many decoration and furniture store(such as IKEA) allow customer to visualize object in virtual version of their homes before purchasing.

\section{REFERENCES}

[1] Jun Lee, JeongHwan Lee, Sora Lim., “ $A$ Mobile based Augmented Reality Service Model on Street Data, and its Implementation", IEEE $39^{\text {th }}$ Annual International Computers, Software \& Applications Conference 2015.

[2] Prakhar Saxena,," Geo-location based augmented reality" IJRET: International Journal of Research in Engineering and Technology, July-2015.

[3] Young-geun Kim and Won-jung Kim , "Implementation of Augmented Reality System for Smartphone Advertisements" International Journal of Multimedia and Ubiquitous Engineering,2014.

[4] Anmol Agarwal, Nitish Kumar Sharma, Piyush Gupta , Prakhar Saxena, Rohit Kumar Pal ,Siddharth Mehrotra, Prof. Prabha Nair and Dr. Manoj Wadhwa,"Mobile Application Development with Augmented

Reality", International Journal of Computer Sciences and Engineering ,2014.
[5] Megha Shetty, Vineet Lasrado, Riyaz Mohammed "Marker Based Application in Augmented Reality Using Android",International Journal of Innovative Research in Computer and Communication Engineering, October 2015. 